\title{
The SERIES model: Development of a Practitioner Focused Emergency Response Evaluation System
}

David Holdsworth and Adam Zagorecki

\begin{abstract}
Purpose - Effective Emergency Response Management (ERM) system evaluation is vital to the process of continual improvement within emergency response organizations. The purpose of this paper is to investigate if an entire ERM system can be captured and encoded within a standardized framework.
\end{abstract}

Design/Methodology/Approach - Employing an exploratory approach we apply a mixed methods case study design and inductive reasoning to analyse documentary evidence provided during the inquest into the London Bombings 2005. We use content analysis to investigate the nature of ERM system data availability and apply principals of Network Theory to iteratively develop a framework within which data can be encoded.

Findings - We find that complex ERM system data can be captured and stored within a standardized framework. We present a conceptual framework and multi-stage mixed methods process, the Standardized Emergency Response Incident Evaluation System (SERIES) model, to support data collection, storage and interpretation. Our findings demonstrate that ERM system evaluation can benefit from the adoption of a standardized mixed-methods approach employing data transformation and triangulation. We also demonstrate the potential of the proposed standardized model, by integrating qualitative and quantitative data, to support interpretation and reporting through the use of appropriate data visualization.

Originality / Value - The SERIES model provides a practical tool and procedural guidelines to capture and share vital ERM system data and information across all emergency services. It also presents an opportunity to develop a large comprehensive multi-incident dataset to support academic inquiry and partnership between academics and practitioners. 
Keywords: Knowledge Management; Emergency Response; London Bombings 2005;

Mixed Method; Data Visualization; Network Theory 


\section{Introduction}

Emergencies are complex, dynamic and ambiguous situations and while our understanding of Emergency Response Management (ERM) continues to benefit from research in the field (Kapucu, 2005; Chen et al., 2008; Bharosa et al., 2009; Eide et al., 2012) identifying and incorporating feedback, especially from practitioners, remains as difficult as it is vital to achieving resilience (Comfort, 2007; Abrahamsson et al., 2010; Pollock, 2013). Issues associated with complexity pose challenges to researchers as much as the responders; often making it difficult to create a conceptual picture of ERM systems, understand their development and compare different incidents. While there are many examples of practitioner led investigation of individual emergency responses (case studies), there are fewer examples of comparative investigations (longitudinal or cross-sectional). Influencing an organisation's ability to learn and adapt, a lack of capacity among practitioners to generate and interpret complex ERM system data could explain the perceived pattern to "continually fail to convert lessons identified from emergency response into embedded lessons learned" (Coles, 2014). While this challenge is not limited to emergency response organisations; learning following response to emergencies is a particularly challenging task (Comfort, 2007; Abrahamsson et al., 2010) and one we believe is compounded by the lack of a standardized framework to support emergency response research.

A further challenge associated with research in general is that associated with bridging the gap between researchers (academics) and research users (practitioners). This challenge was highlighted in the opening editorial for the International Journal of Emergency Services with the stated desire of 'creating a journal that offers a vehicle for more effective communication and sharing of ideas between practitioners and academics' (Wankhade and Murphy, 2012). While this has been a common theme in emergency management research for over 25 years (Neal, 1993; Malone, 1993; Quarantelli, 1993; Wankhade and Murphy, 2012; Trainor et al., 2018; Browne et al., 2018) communication barriers between academics 
and practitioners remain (Browne et al., 2018) and a perceived 'them and us' duality (Trainor et al., 2018) continues to limit collaborative work reducing the potential to improve emergency response effectiveness (Browne et al., 2018). This divide also leads to a failure to capitalise on the potential to exploit the large quantities of data produced by organisations and required by researchers (Benoit et al., 2019). In this paper we present the first stage of research designed to support emergency response evaluation by considering data collection, storage, analysis and interpretation by emergency response practitioners. Based on a content analysis of documents provided during the Coroner's Inquest into the London Bombings of 2005, we analyse the nature of data required and available to support organisational sense-making. Consequently, we propose the Standardized Emergency Response Incident Evaluation System (SERIES) conceptual model designed to incorporate a variety of heterogeneous data sources and types to provide a generic, standardized and scalable process.

\section{Literature review}

To understand how we can improve practitioner engagement in the investigation of ERM system data we considered the nature of ERM systems, how emergency response organisations respond to an incident, and the characteristics of the research environment. Due to the multi-disciplinary nature of Disaster and Emergency research (McEntire and Marshall, 2003; Witt and Lill, 2018) we also consider related Organizational Research (OR).

Emergencies, defined as "events that threatens or causes serious damage to human welfare, the environment or security" (Cabinet Office, 2010), are associated with characteristics like: uncertainty, sudden and unexpected events, the risk of injury or death and high time pressure (Skertich, 2008; Janssen et al., 2009; Hawe et al., 2012; Mishra et al., 2015; Hancox et al., 2018). To function in this environment organisations need to be flexible, adaptable and employ rapid information management processes (Ali, 2016), in part to balance the demands imposed by the emergency itself (procedural tasks addressing agent-generated demand) and the need to manage the organisational response (managerial 
tasks addressing response-generated demand) (Quarantelli, 1997; Franco et al., 2009). We refer to the process of organisational response as the ERM system, the structural and function aspects of the organisation established to support decision making and action by individual actors within the system. While factors such as organisational culture and individual situational awareness influence this system, and as such they are important factors in the effectiveness of the response, they are not explicit components within the system. Becoming increasingly more difficult to coordinate as more organizations become involved (Comfort and Kapucu, 2006; Eide et al., 2012) ERM systems typically rely on a standardized strategy often referred to as Command and Control (C2) or an 'Incident Command System' (ICS). Employing a vertical hierarchy of authority and decision-making these systems implement detailed pre-planned protocols or standard operating procedures (Burkle and Hayden, 2001; Bigley and Roberts, 2001; Rimstad et al., 2014; Groenendaal and Helsloot, 2016; Chang, 2017). While there has been widespread practitioner support for this approach (Buck et al., 2006; Jensen and Thompson, 2016) principles and the assumptions upon which it is based have been challenged (Harrald, 2006; Perry and Quarantelli, 2007; Tierney, 2009; Moynihan, 2009; Groenendaal et al., 2013); often as a result of a perceived lack of empirical research informing their development (Lindell et al., 2005; Franco et al., 2009; Jensen and Thompson, 2016; Groenendaal and Helsloot, 2016). The debate over the efficacy of a hierarchical system establishing clear operational rules (a mechanistic system) as opposed to relying on communication and cooperation to coordinate organised individuals and teams (an organic system) is common in organisational theory (Chang, 2017), especially where organisations need to operate in highly dynamic and complex environments.

The complexity of the emergency environment also presents challenges to researchers in the field, difficulties associated with data collection influencing theoretical frameworks or perspectives that can be practically adopted. Network Theory, representing and quantifying complex and interdependent organisational systems, has been used to 
investigate a variety of aspects of emergency response. The ability of Social Network Analysis (SNA) tools to capture and represent the high density of interaction between responders (Uhr, 2009; Andrew, 2011) and compare formal and informal networks (Dahlberg, 2017) has led to common use (Houghton et al., 2006). However, while methods based on network analysis can address some of the challenges of representing complexity, they do not directly address problems related to accessing, generating and encoding data.

Overcoming the need to generate or collect data in the field, the increasing use of computer simulated environments (Hawe et al., 2012), in part due to their relative low cost and efficiency (Brown and Robinson, 2005), has led to its use to investigate components of ERM systems. However, these approaches typically overlook the complex interactions of the entire ERM system or whole network, a tendency also observed more generally in emergency managment research (Zhou et al., 2011). An alternative option is to observe practitioners during pre-planned emergency exercises (Beerens and Tehler, 2016) providing researchers with a predictable, structured, and more realistic research environment to investigate aspects of response. While the use of emergency response exercises as a data source is common, both as a representation of real-world ERM systems (Dunn et al., 2002; Haar et al., 2013; Alison et al., 2015; Grunwald and Bearman, 2017; Ryan, 2017; Dahlberg, 2017) and as an assessment of exercises themselves (Berlin and Carlström, 2013; Berlin and Carlström, 2015; Edzen and Sein, 2016; Kristiansen et al., 2017; Skryabina et al., 2020) they introduce some threats to validity. The degree to which an exercise represents real world response (ecological validity) depends on the design and nature of the exercise. Where critical variables such as time pressure, information ambiguity and overload are created the validity of exercises as representation of response is often deemed sufficient (Wolbers and Boersma, 2013). However, it is also cited as a limitation (Haar et al., 2013), some taking the view that exercises are often 'divorced from reality, avoiding mutual interaction between teams' (Berlin and Carlström, 2015). This criticism is based on the constructed nature of exercises (Berlin and Carlström, 2013; Kristiansen et al., 2017) leading 
to participants not reacting as they would in a real scenario (Wybo, 2008; Alison et al., 2015). Providing the most ecologically valid environments within which to conduct research; direct observation of ERM systems is challenging because of the unpredictable nature of emergencies and access limitations (Bharosa et al., 2009). For these reasons, case study research tends to rely on diverse methods of data collection involving post incident documentation (e.g. after-action reports or media coverage) and data elicited from responders following an emergency. The ability of emergency responders to recall information is also affected by the complexity and dynamics of emergencies. The effects of heightened arousal have been linked to a decline in memory performance at high stress levels (Deffenbacher et al., 2004; Hope et al., 2012; Morgan and Southwick, 2014; Hope et al., 2016). Memories can be malleable, exposure to misinformation following response leading to errors in eyewitness memory (Morgan and Southwick, 2014; Hope et al., 2016) and subjects have demonstrated a tendency for higher confidence in the accuracy of these false memories (Morgan and Southwick, 2014; Hope et al., 2016). This brief review of Emergency Response related research demonstrates that two key issues require careful consideration before developing an organisational emergency response evaluation system. We must understand what kind of data is available, how can it be gathered, and how reports provided by emergency responders can be integrated with other system data captured during response.

While it is not the purpose of this article to discus definition and application of Knowledge Management (KM), Organizational Memory (OM) and Organizational Learning $(\mathrm{OL})$ in detail, these three linked concepts, highlighted by Dorasamy et al. (Dorasamy et al., 2008), provide a good framework within which to consider the management of data within an emergency response organization. When considered together Dorasamy et al. (Dorasamy et al., 2008) define Knowledge Management as the process of identifying and capturing relevant data for the purposes of organizational functional assessment. Organizational Memory defines the tools utilized to encode and store this data for interpretation by the 
organization and its agents, typically including some form of ICT based database system. Finally, Organizational Learning considers the process of integrating lessons learned into normal organizational function to improve organizational efficiency, adapt to environmental change or increase organizational influence or control. While these definitions represent a simplified answer to a far more detailed discusion, these three categories provide a useful structure to consider wider organizational research and the results presented here.

Considering methodological approaches, disaster and emergency research demonstrates the same paucity of applied mixed-methods as found in the broader field of OR. In their review of 156 disaster related peer reviewed journal articles Witt and Lill (Witt and Lill, 2018) found only 9 reporting mixed-methods. While there is a similar lack of explicit reference to the use of mixed-methods in OR related journals (Molina-Azorín and Cameron, 2010; Bazeley, 2015) researchers have noted that mixed-methods design is required to create a more complete picture of complex systems (Najmaei, 2016) especially in relation to causation of observed phenomena (Krohwinkel, 2015). These examples demonstrate that one of the benefits of mixed-methods approaches lies in the ability to more clearly define research problems and understand complex phenomena (Molina-Azorín and Cameron, 2010; Mertens, 2015); often through the use of triangulation "overcoming the weaknesses of any single method" (Molina-Azorín and Cameron, 2010). While this a term that has been "used, abused, and misinterpreted" (Denzin, 2012); Denzin (1978) distinguishes between data triangulation (collected at different times from different sources), investigator triangulation (different researchers independently collecting and comparing results), methodological triangulation (multiple data collection methods), and theory triangulation (different theoretical interpretations). Although limited, the benefits of mixed-methods as a research choice have been cited in emergency management research. Evaluating disaster response management in Iraq, Al-Dahash and Kulatanga (2017) suggest the use of a mixedmethods approach provided "rich and robust data" resulting in the identification of 
"weaknesses, strengths, and recommendations to enhance the current disaster response practices".

\section{Initial Methodological Approach}

To address the wider question, how can emergency response practitioners collect, store and interpret complex ERM system data to support ERM system evaluation?, we conduct research over two stages. In this paper we report the results of the first stage of research concerning the nature of ERM system data. We construct a conceptual framework to support the development of an emergency response evaluation system and a supporting database tool to collect and encode ERM system data. We then discuss the second stage of research addressing how practitioners can engage with this complex heterogeneous data by utilising data gathered to explore data visualization.

Adopting an exploratory approach we employ a content analysis of evidence documents produced during the Coroner's Inquest into the London Bombings, 2005. Data was collected and analysed to identify the nature and type of data available, and the indicators and metrics required to report on ERM systems. The London Bombings (2005) were selected as a case study example for two reasons. The Emergency Respose to the bombings was one of the largest to an incident in the UK in recent history and involved the coordination and cooperation of multiple emergency response agencies during the inital response phase. The national inquiry following the incident also produced a comprehensive publically available dataset including individual witness testimony from many of the emergency responders involved.

Methods employed to develop the SERIES model are discussed in relation to the following sequential stages,

- analysis of ERM data sources,

- ERM data categorization and transformation, and

- database development and metadata analysis. 
While direct analysis of some of the case study data is presented to demonstrate the application of the SERIES model, we note that the incident data captured within this study may represent a biased, selective sample and therefore should not be used to infer judgements in relation to the actual emergency response employed during the London Bombings.

\section{Emergency Response Data Sources}

In the first phase of the study, a total of 1514 documents were retrieved from the Coroner's Inquest website (in pdf format) and reviewed identifying 739 relevant to the emergency response. Individual pages were collated into original documents resulting in the identification of three categories. We defined documents as primary (generated by responding organisations during the response), secondary (generated by responding organisations after the response) and the transcript of the inquest hearing itself. An initial database was developed to organize and manage documents for later research. Efforts were made to minimise subjective researcher interpretation at this stage. Objective document characteristics were identified and recorded, including the type of document, the source of data (organizational or individual), and the type of data provided (qualitative or quantitative). Appendix A provides description of evidence document types.

A total of 69 documents generated during response (primary documents) were identified. Those included organizational control room records and individual responders' decision and message logs, documents automatically generated during response and handwritten notes provided by individual responders. These contained predominantly quantitative data relating to resource location, the timing of key events and decisions, and communication between organizations and responders.

A total of 112 documents containing data generated after the incident (secondary documents) as part of the debriefing process were identified. This included standardized organizational debrief forms (a type of questionnaire) and witness statements provided by emergency responders. They captured some quantitative data and qualitative descriptions of 
events, observations, informal communication between responders and the rationale behind key decisions made.

The final category of document comprised the transcribed witness testimony of emergency responders questioned during the inquest hearing. These represented semistructured interviews during which responders described their experience and responded to questions including confirmation and elaboration of data provided during the earlier stages of the inquiry investigation. These documents provided unique qualitative data in regards to the responders lived experience during response, explanations of perceived causal factors, phenomena linked to the evolving ERM system, and examination of conflicting data gathered during the inquiry.

The initial evidence review identified common reference to the following key variables relevant to understanding and representing the emerging ERM system:

- geographical location,

- tasks undertaken,

- communication between responders,

- individual role within the command structure, and

- responder observations.

The nature of these characteristics, representative of organizational networks, and the desire to develop a practical data framework tool to support organizational memory (collection and storage of data within a database) led to the methodological choice to employ a Network Theory approach. These network characteristics were incorporated into an initial data encoding framework and database architecture with individual responders recorded as nodes within the network (and database). Organizational documents recording mobilization of resources and formal communication were initially encoded to establish the boundaries of the organizational network, timing of key events and formal communication. While these documents provided some qualitative data (reports of what was observed, short narrative 
descriptions of tasks undertaken, etc.), this data was predominantly quantitative in nature and was easily encoded based on the network perspective adopted.

Utilizing this initial quantitative network data, individual responders first in attendance at one of the bomb sites were identified and further primary evidence (e.g. decision logs recorded by individuals during the response), secondary evidence (e.g. organisational debrief reports submitted by individuals), and where available inquest testimony (hearing transcript) was then encoded. This evidence provided further quantitative data (e.g. the type and timing of tasks undertaken, movement between locations, informal communication between personnel), and introduced qualitative data based on these individuals reflecting on events.

The whole network between responders that emerged during data entry, consisting of component distinct networks representing shared locations, tasks, and face to face communication was used to apply a loose snowball procedure starting with those personnel who were first in attendance. This method was chosen (over random sampling for example) because of its ability to efficiently collect data with a higher degree of connectedness (shared tasks, communication, operation in the same location, etc.) (Newman, 2010). This allowed us to identify individuals who interacted during the incident, data relevant to these individuals being encoded, and the process continuing until the value of information in relation to generating new and overlapping data records reduced to a point where by a new starting point (person) was determined to be necessary. The choice of new starting point included recognition of the importance of generating a dataset that represented each of the responding organisations (Uhr and Johansson, 2007) to support the overall goal of representing the whole ERM network.

\section{Specific Methods and Results}

\section{Data Categorization and Transformation}

Adopting an inductive approach (identifying general typologies and categories from specific raw data) the content of qualitative data records was iteratively reviewed during data 
encoding to identify hierarchical categories within which recorded narrative descriptions of tasks and locations could be assigned. The network approach adopted also lead to the identification of two further categories within which qualitative responder reports relating to their experience of the organizational response could be assigned.

\section{ERM Task and Location Data}

Initial qualitative reports of tasks undertaken by responders and their location were recorded verbatim resulting in discrete tasks and locations being described in a number of ways. This lack of a singular standardized category for each task or common definition for a location complicates the process of content analysis and would introduce challenges associated with intercoder agreement and reliability. For this reason this data was iteratively reviewed to group records and develop hierarchical data categories.

A categorization scheme for specific locations was quickly identified based on geographical properties including, for example locations defined as Remote, (away from the incident scene, e.g. Organisational Control rooms, vehicles en route to the scene) and On Scene (locations within the immediate incident area).

Categorization of tasks was more complex. Initially, three categories of task emerged:

1. Direct Intervention - tasks directly reducing the impact of the emergency (e.g. search and rescue or first aid),

2. Operations Support - tasks indirectly involved in resolving the incident by supporting Direct Intervention, (e.g. transporting equipment or personnel to the scene of operations), and

3. Command and Control - tasks required to coordinate communication, control and supervision of tasks, (e.g. logging incident information and radio messages).

All reported tasks were recorded as unique records capturing a narrative description of the task, time and the person undertaking the task. Periodically these records were 
analyzed adopting a conventional content analysis approach, allowing categorization to flow from the data rather than extending an existing framework or theory (Hsiieh and Shannon, 2005; Zhang and Wildemuth, 2009). Qualitative records of tasks were grouped into clusters determined by their location, time and if they were shared tasks. Descriptions of the tasks were reviewed to identify definitional characteristics resulting in codes for individual tasks and categories where links between tasks were identified. Over several iterations a hierarchy of task categories developed based on reported tasks and logical extensions of these tasks. Appendix B provides the complete task data framework.

\section{Emergency Responder Comments and Observations}

All qualitative responder reports recorded were reviewed to identify the elements of the ERM network to which they referred. This resulted in the identification of two categories of responder reports we define as Observations and Comments. The Observations related to specific elements of the ERM system or emergency environment, in a specified place and time. They could be directly linked to other network variables within the database structure. A total of 46 observations were recorded, analysis of which identified:

- 20 references to the state of the environment, e.g. "09:04:15 - The smoke was very thick. It was hard to breathe",

- 3 references to suspected trigger events, e.g. "09:27:00 - you could see people coming out with... covered in soot and injuries. I think it was then fairly obvious that an explosion had occurred",

- 19 references to Agent-Generated Demands, e.g. "09:01:20 - passengers started exiting the Underground station who needed immediate first aid attention",

- 15 references to Response-Generated Demands, e.g. "09:20:15 - Radios not working in Tunnel. Sent a runner to request more equipment".

The second category, Comments, captured general comment on the experience of the responder within the ERM system and environment, not linked to a specific network 
attribute, place or time. A total of 21 Comments were recorded, analysis of these statements identifying:

- 15 records referencing Response-Generated demands, e.g. "We were unaware that the first ambulance to attend was to assess the situation and not start ferrying people away",

- 5 records relating to Agent-Generated demands, e.g. "I set my strategy for my officers which was preserving life, assisting casualties, preserving the scene and identifying witnesses and evidence",

- 2 records describing emergent behaviour and procedural deviation, e.g. "with regards to rail line power isolation - I can't remember having had it thoroughly confirmed. In this respect during early stage procedure went out the window",

- 2 records considering counterfactuals or 'What ifs?', e.g. "with regards to more information or assistance during the early stages of the incident this would not have affected chosen tasks or the immediate outcome of activities".

\section{Database Structure and Meta Data}

A mixed methods case study approach in the form of encoding and transforming quantitative and qualitative data simultaneously over iterative stages was chosen because of the importance of the relationship between the development of the data encoding framework and the supporting database tool. While a detailed description of the structure of the database is beyond the scope of this article the following example demonstrates the benefits of this research methods choice.

When encoding data relating to multiple responders undertaking a shared discrete task it was discovered that, from a network perspective, while the shared task occurred in the same place it did not always occur at the same time. For example, responder $A$ begins first aid on a victim, responder $B$ joins her later. Responder $A$ is then re-tasked leaving responder $B$ to finish the first aid task. The initial database structure recorded a description of each discrete task as a unique record in a 'Task Undertaken' table linked to the responder 
record in a 'Personnel' table (see Figure 1A). As the task data framework was introduced, creating a 'Task Category' table in the database, the discrete task record was linked to the relevant task type in the task category table, with all relevant responders (multiple records in the Personnel table) being linked to the single task record (see Figure 1B). This created a problem because the time of this record was captured relative to the task and not each responder, failing to reflect the fact each responder could support this discrete task at different times. In this configuration the database did not reflect the environment under investigation. A further final structural alteration to the database was required to record a separate task record for each responder, creating multiple records for one discrete task linked by adding a common value in the Tasks Undertaken table (see Figure 1C).
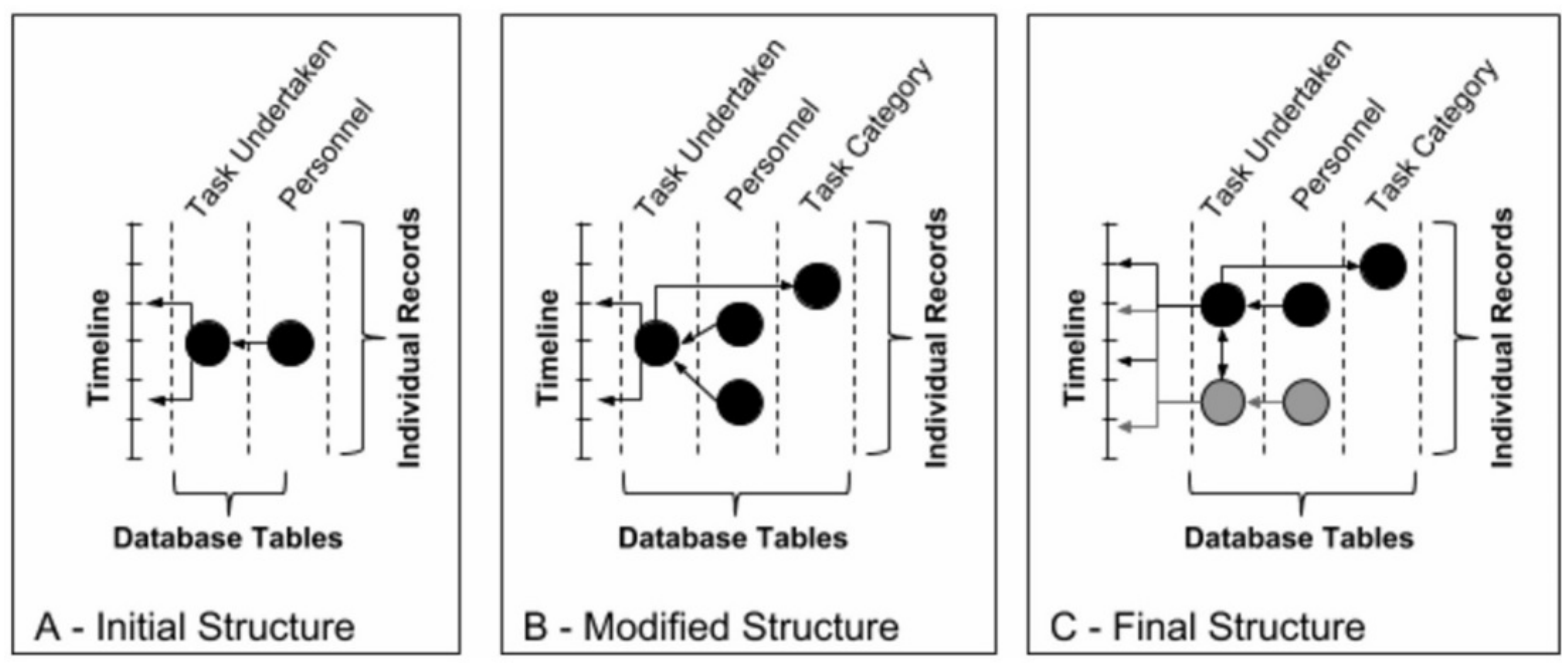

Figure 1. Relationship between task record tables in the SERIES database

This process of development highlights the value of both the exploratory and interactive-convergent mixed methods approach adopted. By collecting qualitative and quantitative data together (convergent) and iteratively analysing this data to amend the data collection and encoding method (interactive) the resulting structure of the database (that will encode future data) reflects the characteristics of the specific environment from within which the data will be generated and the nature of the system under investigation. We believe this to be a good example of how knowledge management systems should complement organizational memory systems to ensure data is captured and stored in such a way as to 
reflect contextual factors within the organizational environment that should influence how data is interrogated or interpretted later.

To facilitate evaluation of the proposed model, specifically the value of mixing qualitative and quantitative data, meta-data relating to each database record was captured. This included recording the relationship between individuals reporting information and to whom it related, categorized as Self (reporting details relevant to only themselves), Self \& Others (reporting information relevant to themselves and other responders), or Others (reporting information not directly relating to themselves). Coherence metrics, similar to those suggested by Fetters, et. al. (2013), were also captured. These provided a measure of the relationship between multiple evidence sources (documents or people) linked to single records based on the following categories:

- Replicating (containing the same information),

- Refining (increasing the detail or accuracy of the record),

- Supplementing (providing additional detail within the record),

- Triangulating (multiple record sources collectively creating new information), and

- Conflicting (information contained or reported differed between each source).

A total of 1071 records were encoded within the SERIES database (1 record is equivalent to 1 responder linked to 1 task, location, comment, etc). The majority of these records related to information exchange (593) and node location (309). Table 1 presents the source of individual records encoded in relation to network variables and source document type. 
Table 1. Source of Encoded SERIES Database Records

\begin{tabular}{|c|c|c|c|c|c|c|c|}
\hline & \multirow[b]{2}{*}{$\begin{array}{c}\text { Source } \\
\text { Document }\end{array}$} & \multicolumn{6}{|c|}{ Encoded Record Type } \\
\hline & & Location & $\begin{array}{c}\text { Information } \\
\text { Exchange }\end{array}$ & Task & $\begin{array}{c}\text { Command } \\
\text { Role }\end{array}$ & Observation & Comment \\
\hline \multirow{4}{*}{$\begin{array}{l}\text { Primary } \\
\text { Evidence }\end{array}$} & Command Logs & 5 & 3 & - & - & - & - \\
\hline & $\begin{array}{l}\text { Control } \\
\text { Records }\end{array}$ & 144 & 389 & 2 & 2 & - & - \\
\hline & $\begin{array}{l}\text { Message } \\
\text { Transcript }\end{array}$ & 1 & 11 & & - & - & - \\
\hline & Decision Logs & 2 & 13 & 3 & - & 1 & - \\
\hline \multirow{4}{*}{$\begin{array}{l}\text { Secondary } \\
\text { Evidence }\end{array}$} & $\begin{array}{l}\text { Debrief - } \\
\text { Personal }\end{array}$ & -- & 16 & 1 & 2 & 2 & 5 \\
\hline & $\begin{array}{c}\text { Debrief - } \\
\text { Organizational }\end{array}$ & - & - & - & - & - & 3 \\
\hline & $\begin{array}{l}\text { Witness } \\
\text { Statement }\end{array}$ & 11 & 4 & 2 & - & 1 & - \\
\hline & $\begin{array}{l}\text { Witness } \\
\text { Testimony }\end{array}$ & 146 & 157 & 86 & 2 & 42 & 15 \\
\hline
\end{tabular}

Figure 2 displays results that relate to records provided by individual responders (not organizational documents). Records are categorized by the network variable to which they refer and the relative relationship between the source (reporting) individual and the records subject individual.

\section{$\%$ SERIES Database Records}

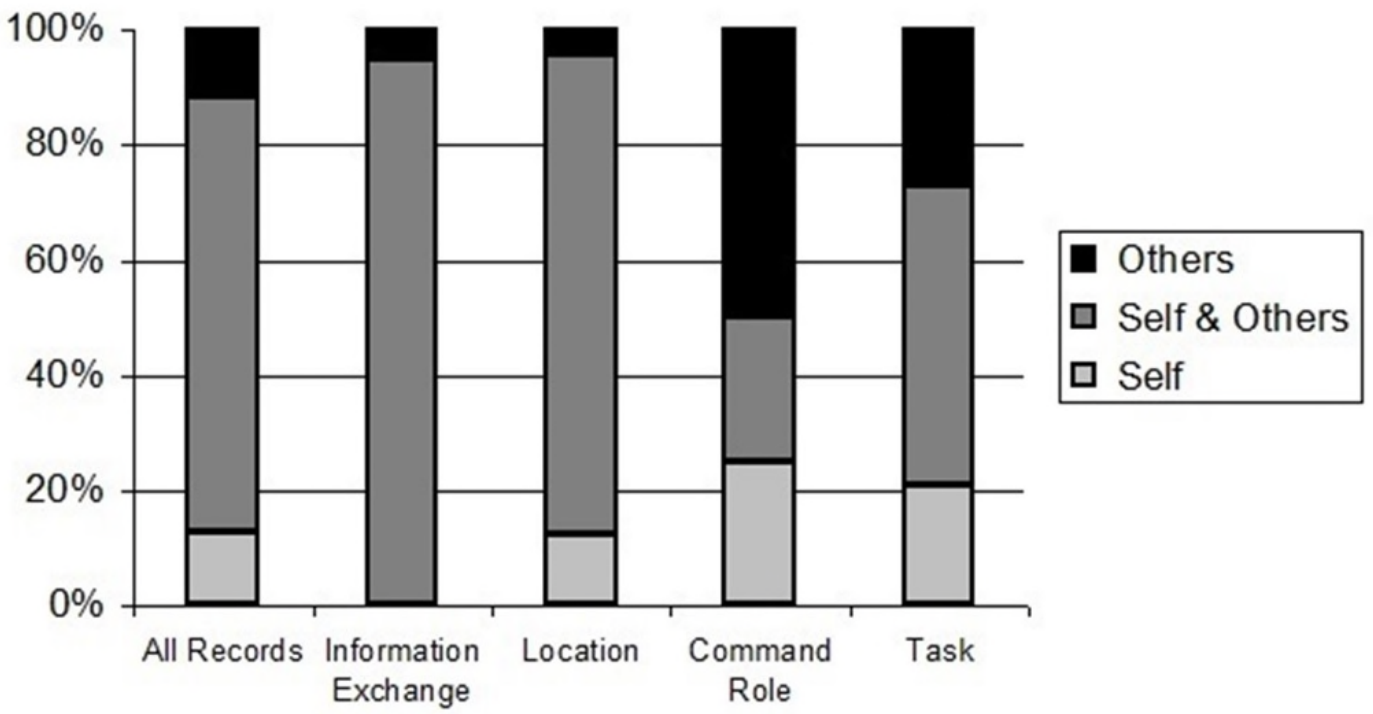

ERM System Variable

Figure 2. Chart representing the relative source type for SERIES database records 
While there is no clearly identifiable trend in either Table 1 or Figure 2 these results highlight the value in generating data from a variety of sources and the potential to identify data relating to a large group of connected individuals from a relatively small sample group. Over $75 \%$ of records related to both the reporting individuals and someone else, records relating to 129 different emergency responders being generated from reports provided by only 16 emergency responders. This demonstrates the value of the dataset provided by this case study and the methods employed by the inquest investigators in terms of collecting data from different sources (data triangulation) and different methods (methodological triangulation) (Denzin, 1978). These results also suggest added value in relation to combining theoretical approaches (theory triangulation). Providing data relating to the more objective, predominantly quantitative ERM system attributes, a network theory approach has been employed to make sense of this data, facilitating representation and interrogation of interdependent variables. Data collected from participant reports via questionnaire and interview methods provides more subjective, predominantly qualitative contextualized explanations related to the development of the ERM system structure, how it actually functioned and the relationship between the ERM network attributes captured earlier. The integration of this latter data and methodology, representing characteristics of a sociological or ontological approach, with the earlier quantitative network data defines the mixed methods research adopted here and proposed for the SERIES model.

Table 2 presents results of the frequency of recorded coherence metrics including the type of source document and network attribute to which the record relates. 
Table 2. Frequency of Coherence Metrics Observed in SERIES Database Records Relative to Record Source Document Type and ERM System Variable Relative to Record Source Document Type and ERM System Variable

\begin{tabular}{cccc}
$\begin{array}{c}\text { Coherence } \\
\text { Metric }\end{array}$ & Frequency & Source Document & ERM system variable \\
\hline Triangulate & 62 & $\begin{array}{c}\text { Command Log } \\
\text { Control Record } \\
\text { Witness Statement } \\
\text { Witness Testimony }\end{array}$ & Information Exchange \\
& 17 & $\begin{array}{c}\text { Witness Testimony } \\
\text { Organizational Report }\end{array}$ & Information Exchange \\
\hline Replicate & & Control Record & Tocation \\
\hline Supplement & 9 & Debrief - Personal & Information Exchange \\
& & Witness Testimony & Task
\end{tabular}

Due to the limited data sample, no significant relationship can be drawn from these results. However, the presence of each type of coherence metric indicates the value of integrating multiple record sources. This is demonstrated by the relatively high occurrence of data triangulation, attributed in part to the process of identifying the time tasks were undertaken and responders moved through different locations. While responders could recall and report the series of events (tasks and location details) as they experienced them, record times were typically identified within the quantitative network data recorded within organizational documents.

\section{The SERIES Model}

Based on our findings we propose the Standardized Incident Evaluation System (SERIES) model. We describe how it should be applied in terms of future data collection and how it integrates quantitative network data and (predominantly) qualitative responder reports within a single data framework supported by the SERIES database. We consider how the 
SERIES data framework, in particular the coding categories developed, will support data collection and storage. In the final discussion section we introduce the next stage of research (beyond the scope of this paper) designed to apply the SERIES model to further case studies. This will address issues of generalization as they relate to the validity of the assertion that the SERIES model can be applied to other ERM systems. We also consider the development of data visualization methods to support practitioner interpretation of SERIES data.

Figure 3 represents the three stages of data collection and proposed data visualization based on an embedded mixed methods approach.

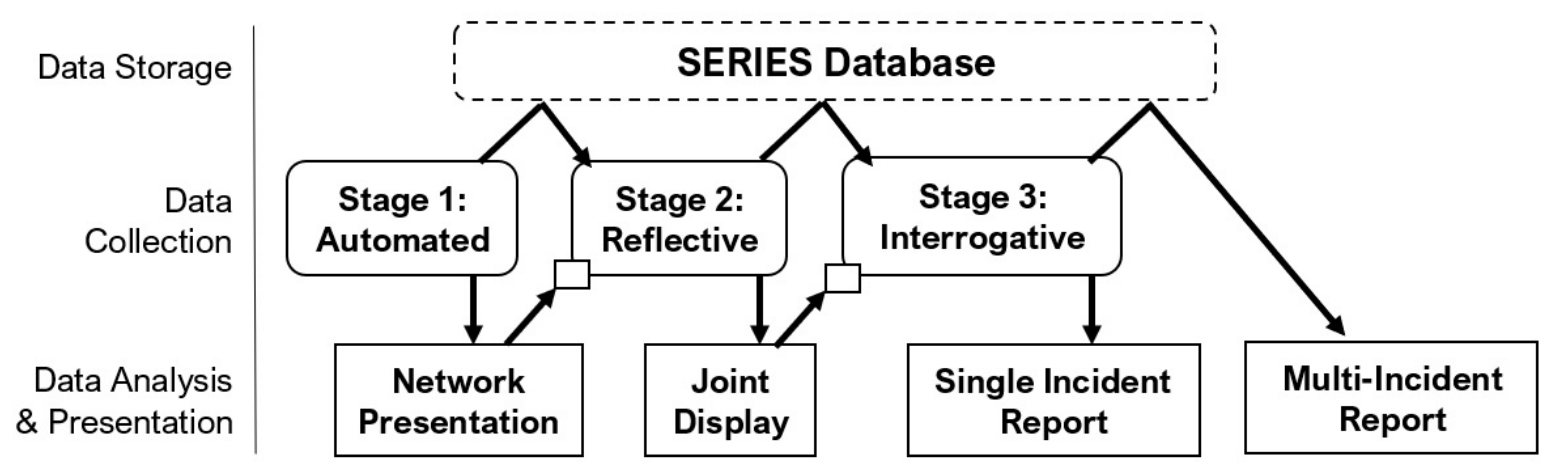

Figure 3. The SERIES Model

\section{Stage 1 - Automated Data Collection}

The first stage comprises encoding data generated during response as part of the normal ERM operations. The results of the content analysis demonstrate that this stage would generate predominantly quantitative data relating to responder locations and the timing of key events recorded in messages to organizational control rooms. Many of these ERM organizational functions rely on computerized systems, such as resource mobilization software to assign vehicles to locations, presenting an opportunity to automate the link between these organizational systems and the SERIES database. Where this link is not viable (for example encoding handwritten logs) this data is entered as recorded, limiting room for subjective interpretation at the time of encoding. Utilising quantitative network data, 
a temporal graph representing the evolving ERM system, key events and communication is generated for visual analysis and to support the next stage of data collection.

\section{Stage 2 - Reflective Data Collection}

In the second stage, emergency response personnel are provided with a Temporal Graph produced at the Stage 1. They are asked to validate data represented by the graph and provide additional quantitative data relating to network characteristics (tasks, locations, communication, etc). Our findings demonstrate that this stage would also include reflective comments and observations (qualitative judgement relating to the ERM system). The resulting dataset, comprising both qualitative and quantitative data, is presented for analysis, possibly via a joint display (see Figure 5 for example).

\section{Stage 3 - Interrogative Data Collection}

Data collected during Stages 1 and 2, including visualizations, are intended to serve as a tool for investigators and/or researchers to allow them to review and analyse the incident. Analysis of the witness testimony identified that data collected during the earlier stages of investigation (automated and reflective in the SEIRES model) could be used to identify specific areas of interest, conflict or omission of data. Relevant responders can be identified (determined by location, tasks undertaken, etc.) and interviewed. Further analysis is undertaken if needed, following which a final report is prepared.

\section{Data Visualization}

To this point we discussed development of a Knowledge Management process and an Organizational Memory tool (the SERIES database) to collect and encode ERM system data in an accessible format. The next step of our research focuses on how emergency response practitioners can interpret this complex data to support the Organizational Learning function, integrating this organizational experience into future organizational practice.

We propose that the issue of interpretting complex heterogeneous data be supported by developing a data visualization component. The development of these visualizations must consider both the nature of data required and available relating to ERM systems (identified 
during this research) and the specific challenge of presenting this complex data in such a way as to make it accessible to practitioners. However, we can begin to consider how these vizualizations can be developed based on the nature of the data and encoding framework defined within the SERIES model.

In this first example, the development of coding categories for emergency response tasks allows this data to be grouped by higher level categories reducing the complexity of the dataset to a point where it can be visually analyzed without the need for complex network analysis.

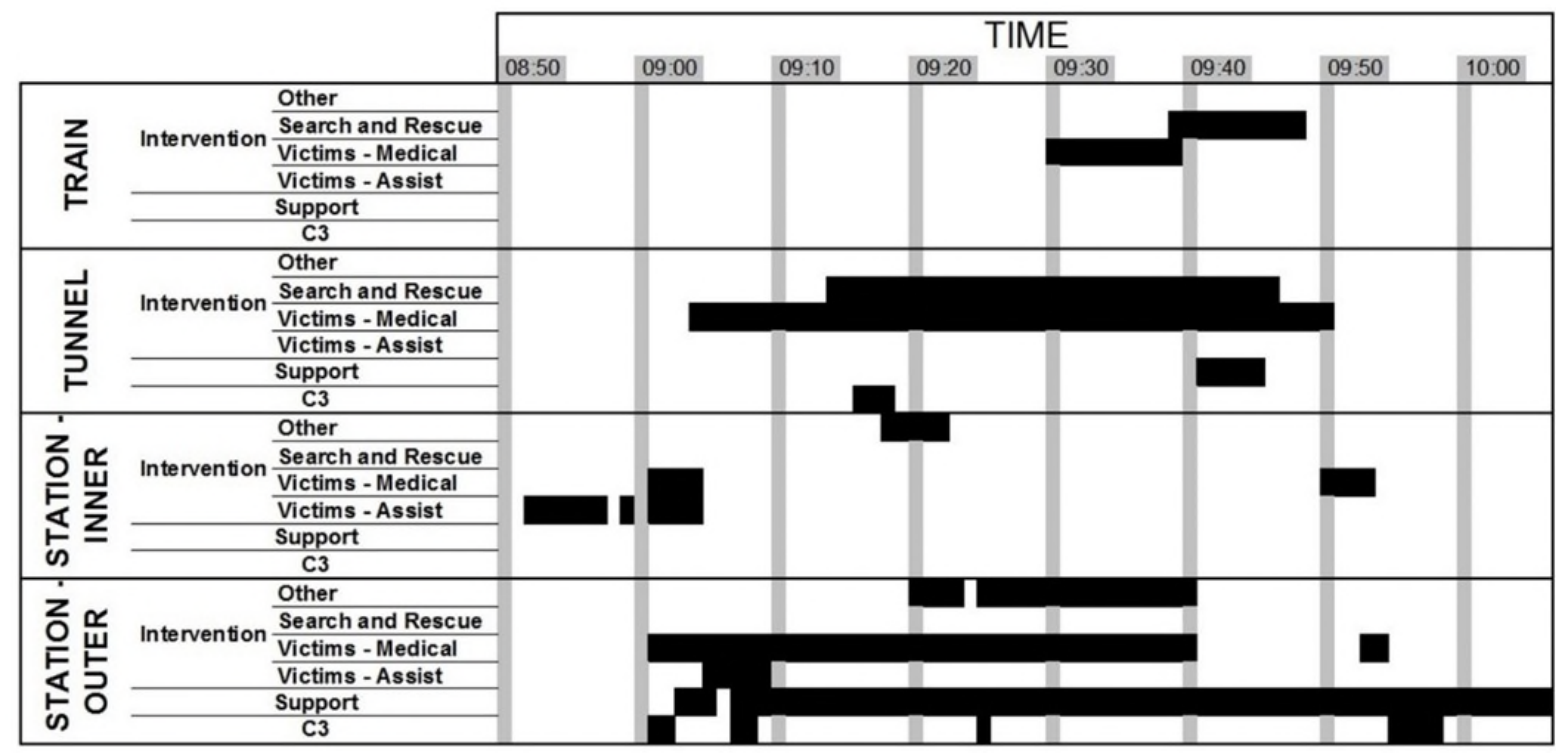

Figure 4. Time-line of tasks undertaken by emergency responders at Aldgate

Underground Station

In this example, presenting data encoded from ducuments relating to one of the bomb sites, a total of 91 reported tasks comprising 32 discrete task types are reduced to 6 task categories presented over 4 location categories. In the context of the case study data, Figure 4 demonstrates that while initial tasks were located inside the station; after approximately 15 minutes this ceased and later tasks were limited to outside the station and in the underground tunnel.

Figure 5 demonstrates how quantitative and qualitative data could be jointly displayed (after the reflective stage) to support the interrogative stage of data collection. 
Each type of record (location, command role, observation, etc.) can be displayed side by side along a single timeline allowing each record to be considered in the context of the overall picture, relative to that individual. In the case of non-specific Comments (reports not linked to a specific time or location), viewed alongside the overall timeline these reports can also be interpreted in the context of the whole complex ERM network relative to that person. Figure 5 presents data provided by and related to a single emergency responder demonstrating one of the ways this combined data could be visualized.

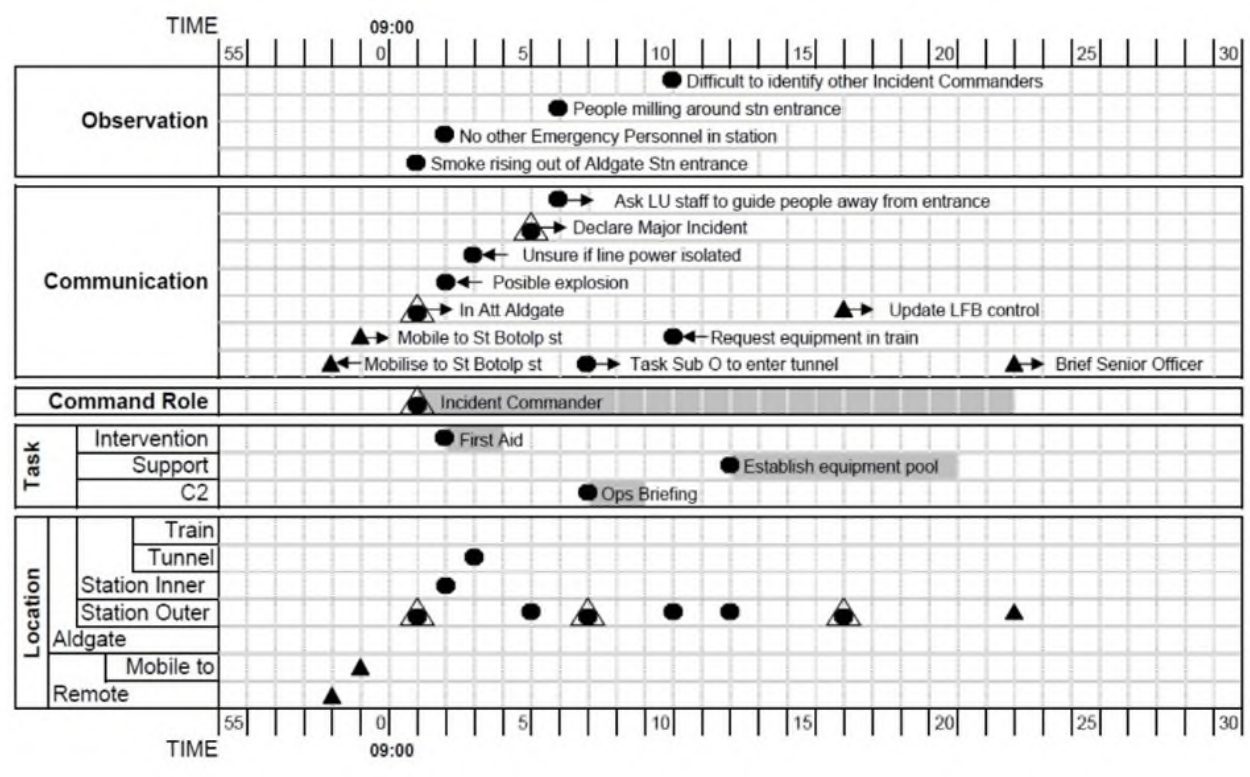

\begin{tabular}{|c|c|}
\hline \multirow{2}{*}{\multicolumn{2}{|c|}{\begin{tabular}{l}
\multicolumn{1}{c}{ Comments } \\
Fire crews unaware of the role of \\
initial LAS crews
\end{tabular}}} \\
\hline & \\
\hline \multicolumn{2}{|c|}{$\begin{array}{l}\text { Assessment of bomb type / hazard } \\
\text { based on injuries presented by } \\
\text { casualties }\end{array}$} \\
\hline \multicolumn{2}{|c|}{$\begin{array}{l}\text { More info or support would not } \\
\text { have influenced early stages of } \\
\text { response }\end{array}$} \\
\hline \multicolumn{2}{|c|}{$\begin{array}{l}\text { Unsure if / when rail line power was } \\
\text { confirmed isolated }\end{array}$} \\
\hline \multicolumn{2}{|c|}{$\begin{array}{l}\text { LFB Equipment dump did not } \\
\text { include sufficient medical supplies }\end{array}$} \\
\hline \multicolumn{2}{|c|}{$\begin{array}{l}\text { We considered limiting use of Hand } \\
\text { Held Radio because of Secondary } \\
\text { Devices }\end{array}$} \\
\hline \multicolumn{2}{|r|}{ Key } \\
\hline & $\begin{array}{l}\text { Data provided by subject } \\
\text { node }\end{array}$ \\
\hline $\boldsymbol{\Delta}$ & $\begin{array}{l}\text { Data provided by other } \\
\text { source }\end{array}$ \\
\hline$\Delta$ & $\begin{array}{l}\text { Data provided by subject } \\
\text { node and other source }\end{array}$ \\
\hline$\rightarrow$ & $\begin{array}{l}\text { Communication from } \\
\text { subject node to other }\end{array}$ \\
\hline$\Delta \leftarrow$ & $\begin{array}{l}\text { Communication from other } \\
\text { to subject node }\end{array}$ \\
\hline
\end{tabular}

Figure 5. Joint display of ERM network records and reflective statements relating to a single emergency responder during the London Bombing

In this example, data records relating to ERM network attributes and responder observations can be presented along side each other on a timeline presenting a more complete contextualised picture of that respoders role within and comment about the ERM system. All the records relating to this agent can be displayed (circles indicating data provided by the subject, triangles indicating data relating to the subject but provided by another source). This allows data relating to different ERM attributes to be displayed and considered in context. The context can then be considered when interpreting the more general comments made by this individual responder. By embedding the quantitative data (representing the formal characteristics and relationships between variables) and qualitative 
data (providing insight into the causal factors or phenomena influencing these relationships) within a single framework (provided by the SERIES model) one data type supports the other allowing contextual factors that may previously have been obfuscated within a large complex dataset to be considered.

\section{Discussion}

Based on the results presented we argue that an emergency response evaluation system intended to support emergency response organizations should capture both qualitative and quantitative data within a standardized framework. Data integration and transformation enriches its potential value to investigators by making it more readly available and supporting a variety of analytical approaches. This necesitates the use of a mixed methods approach, the choice of design being closely linked to it's anticipated use (Bryman and Bell, 2015). For this reason it is appropriate to consider the methodological choices employed during the development of the SERIES model and how this differs from the proposed application of the model and processes.

\section{Research Development}

The design and method used to conduct the content analysis demonstrated characteristics of both an interactive-convergent and an explanatory-sequential mixed methods approach. Collecting qualitative and quantitative data together at the design level facilitated the iterative analysis required to develop the data encoding framework and database - these constitute characteristics of an interactive-convergent design and embedding method (Fetters et al., 2013; Creswell, 2014; Bryman and Bell, 2015). The later snowball sampling method utilized quantitative data to inform the selection of specific responders to gather further predominantly qualitative data, an explanatory-sequential design (Fetters et al., 2013; Creswell, 2014; Bryman and Bell, 2015). The exploratory approach adopted, using both qualitative and quantitative data to build a comprehensive understanding of the case reflects key characteristics of case-study design (Fetters et al., 2013). This design choice made, in part for practical reasons (the existence of a large 
accessible published data set), and because it supported the desire to understand structural and content variables within an ERM system.

\section{Research Application}

We propose that some form of visual analysis of data collected during the automated stage should be provided to support data collection during the proceeding reflective stage (characteristic of the a convergent-interactive design). Analysis of combined data (automated and reflective) will then inform both the selection of individuals and analysis of data during the final interrogative stage. This results in a model best characterized as a multi-stage design. Centred around the data encoding framework and SERIES database, the method employed by the SERIES model is defined by the requirement to embed both qualitative and quantitative data together. This is critical because this method has demonstrated potential to increase the accuracy of data gathered during the automated and reflective stage.

By providing responders with the network data (in the form of a visualization) encoded during the automated stage for them to refer to during their reflective data collection we may address some of the potential bias or errors associated with witness reports discussed earlier. Any potential data errors introduced and encoded during the automated stage can also be identified. Regardless of any increase in the accuracy of data collected; the combination of qualitative and quantitative data providing overlapping reports of aspects of the ERM system and environment will increase confidence where they are consistent (Luyt, 2012). In the cases where there are inconsistiencies in the data - they identify the need for further investigation, during the interrogative stage. Employing mixed methods to investigate organizational emergency response not only provides more detailed and informative data than could otherwise be produced by employing qualitative and quantitative methods independently, it is a requirement to understand these complex systems and support organisation sense-making. 


\section{Research Value and Future Work}

Our results demonstrate the value of data transformation, specifically in the case of task and location network data (see Figure 4 and 5). We also demonstrate the value of data triangulation, a process supporting construct validity(Dubois and Gibbert, 2010; Yin, 2014, p.47) or the degree to which a study investigates what it claims to investigate(Gibbert and Ruigrok, 2010). From the perspective of a single case, this also supports what Maxwell(1992) terms 'descriptive validity' refering to the accuracy of case representative data. However, the purpose of the SERIES model is to provide a standardized model. For this reason, the next stage of research will build on these results to address the question of generalization raised by developing the model based on a single case study. The model will be used to collect and encode data gathered following a highrise building fire exercise, collecting data directly from participating firefighters. This will provide data to inform analysis of the SERIES data collection and encodeing framework and generate a dataset from which a range of visualization designs can be produced and tested. While further research is needed to develop these aspects of the SERIES model, the accessibility and structure of the dataset can facilitate a range of network analysis and data visualization methods. Figure 5 also demonstrates the potential to explore the incorporation of qualitative and quantitative data through joint display, an ongoing area of interest within mixed methods research (Guetterman et al., 2015).

Our results indicate that the SERIES model demonstrates the potential to standardize emergency response data, supporting organizational knowledge management and exploiting potential research opportunities. It also complements existing organizational procedures for data collection and investigation reducing burden on organizations to employ this model. As such it is offered as a proof of concept. This is an important stage in the development of an applied tool because it should generate the support (in the form of future access to data collection opportunity) required for further research. Applied to more incidents the growing data set will be used to further refine elements of the model such as the 
categorisation of emergency response tasks. Further application is also required to address accepted existing research limitations.

The London Bombings (2005) as a case study have been used by many researchers (Strom and Eyerman, 2008; Cocking, 2013; Strandh, 2015; Glasgow et al., 2018) however, the degree to which it is representative within the domain remains an assumption with the potential to affect external validity. The case study method employed to investigate design and method integration differs significantly from the application of the proposed multi-stage method. The snowball sample method employed during data collection can generate a biased representation of a population (Heckathorn, 1997; Newman, 2010), affecting internal validity and reliability. Further research, including the application of this model to other incidents of varying type and size, will provide more data to address these issues. The integration of technological solutions to support or study emergency response activities, such as the use of helmet mounted cameras to gether data during fire service exercises (Cohen-Hatton et al., 2015; Groenendaal and Helsloot, 2018), presents the opportunity to improve ERM system evaluation and integrate aspects of this within the actual real-time response.

We propose that the work described in this paper should be considered as a neccesary and currently overlooked starting point that we believe is pre-requisite for addressing many challenges highlighted within the emergency response domain. It also offers an opportunity to address the practitioner $\backslash$ academic divide and support innovation in future research. The application of the SERIES model not only provides a vehicle to generate large datasets to the benefit of both academics and practitioners, it demonstrates the potential benefit of engagement between these two communities. 


\section{References}

Abrahamsson, M., Hassel, H. and Tehler, H. (2010) 'Towards a System-Oriented Framework for Analysing and Evaluating Emergency Response'. Journal of Contingencies and Crisis Management, 18(1), pp. 14-25. DOI: 10.1111/j.1468-5973.2009.00601.x.

Al-Dahash, H.F. and Kulatunga, U. (2017) ‘Evaluating Disaster Response Management Stemming from War Operations and Terrorism in Iraq: A Methodological Approach'. In 13th International Postgraduate Research Conference 2017. Manchester, U.K.: University of Salford, Manchester, pp. 466-477. Available at: http://usir.salford.ac.uk/43853/.

Ali, I. (2016) 'Doing the Organizational Tango: Symbiotic Relationship between Formal and Informal Organizational Structures for an Agile Organization'. Interdisciplinary Journal of Information, Knowledge, and Management, 11, pp. 55-72.

Alison, L. et al. (2015) 'Decision Inertia: Deciding between Least Worst Outcomes in Emergency Responses to Disasters'. Journal of Occupational and Organizational Psychology, 88(2), pp. 295-321. DOI: 10.1111/joop.12108.

Andrew, T. (2011) 'Analysis of Command and Control Networks on Black Saturday'. The Australian Journal of Emergency Management, 26(3), pp. 20-29. Available at: https://ajem.infoservices.com.au/items/AJEM-26-03-06.

Bazeley, P. (2015) 'Mixed Methods in Management Research : Implications for the Field'. Electronic Journal of Business Research Methods, 13(1), pp. 27-35. DOI: 10.4135/9780857020109.

Beerens, R.J.J. and Tehler, H. (2016) 'Scoping the Field of Disaster Exercise Evaluation - A Literature Overview and Analysis'. International Journal of Disaster Risk Reduction, 19(May), pp. 413-446. DOI: 10.1016/j.ijdrr.2016.09.001.

Benoit, S. et al. (2019) 'Bridging the Data Divide between Practitioners and Academics to Leverage Each Other's Resources'. Journal of Service Management, 30(5), 
pp. 524-548. DOI: 10.1108/JOSM-05-2019-0158.

Berlin, J.M. and Carlström, E.D. (2013) 'The Dominance of Mechanistic Behaviour: A Critical Study of Emergency Exercises'. International Journal of Emergency Management, 9(4), p. 327. DOI: 10.1504/IJEM.2013.059878.

Berlin, J.M. and Carlström, E.D. (2015) 'The Three-Level Collaboration Exercise Impact of Learning and Usefulness'. Journal of Contingencies and Crisis Management, 23(4), pp. 257-265. DOI: 10.1111/1468-5973.12070.

Bharosa, N., Lee, J. and Janssen, M. (2009) 'Challenges and Obstacles in Sharing and Coordinating Information during Multi-Agency Disaster Response: Propositions from Field Exercises'. Information Systems Frontiers, 12(1), pp. 49-65. DOI: 10.1007/s10796009-9174-z.

Bigley, G.A. and Roberts, K.H. (2001) 'The Incident Command System: HighReliability Organizing for Complex and Volatile Task Environments'. Academy of Management Journal, 44(6), pp. 1281-1299. DOI: 10.2307/3069401.

Brown, D.E. and Robinson, C.D. (2005) 'Development of Metrics to Evaluate Effectiveness of Emergency Response Operations'. In 10th International Command and Control Research and Technology Symposium The Future of C2. McLean, VA.

Browne, K.E., Connell, C.O. and Meitzner, L. (2018) 'Journey Through the Groan Zone with Academics and Practitioners : Bridging Conflict and Difference to Strengthen Disaster Risk Reduction and Recovery Work'. International Journal of Disaster Risk Science, 9(3), pp. 421-428. DOI: 10.1007/s13753-018-0180-y.

Bryman, A. and Bell, E. (2015) Business Research Methods. 4th Edition. Oxford, U.K.: Oxford University Press.

Buck, D.A., Trainor, J.E. and Aguirre, B.E. (2006) 'A Critical Evaluation of the Incident Command System and NIMS'. Journal of Homeland Security and Emergency Management, 3(3), pp. 1-27. DOI: 10.2202/1547-7355.1252. 
Burkle, F.M. and Hayden, R. (2001) 'The Concept of Assisted Management of LargeScale Disasters by Horizontal Organizations.' Prehospital and Disaster Medicine, 16(3), pp. 87-96. DOI: 10.1017/S1049023X00025875.

Cabinet Office. (2010) Responding to Emergencies the Uk Central Government Response Concept of Operations. Available at:

https://assets.publishing.service.gov.uk/government/uploads/system/uploads/attachment_da ta/file/192425/CONOPs_incl_revised_chapter_24_Apr-13.pdf.

Chang, H.H. (2017) 'A Literature Review and Analysis of the Incident Command System'. International Journal of Emergency Management, 13(1), pp. 50-67. DOI: 10.1504/IJEM.2017.081193.

Chen, R. et al. (2008) 'Coordination in Emergency Response Management'. Communications of the ACM, 51(5), pp. 66-73. DOI: 10.1145/1342327.1342340.

Cocking, C. (2013) 'The Role of "Zero-Responders" during 7/7: Implications for the Emergency Services'. International Journal of Emergency Services, 2(2), pp. 79-93. DOI: 10.1108/IJES-08-2012-0035.

Cohen-Hatton, S.R., Butler, P.C. and Honey, R.C. (2015) 'An Investigation of Operational Decision Making in Situ: Incident Command in the U.K. Fire and Rescue Service'. Human Factors, 57(5), pp. 793-804. DOI: 10.1177/0018720815578266.

Coles, E. (2014) (10:Occasional Papers Series) Learning the Lessons from Major Incidents : A Short Review of the Literature. Emergency Planning College Available at: https://www.epcresilience.com/EPC.Web/media/documents/Papers/Occ10-Paper.pdf.

Comfort, L.K. (2007) 'Inter-Organizational Design for Disaster Management: Cognition, Comunication, Coordination, and Control'. Journal of Seismology and Earthquake Engineering, 9(1), pp. 61-71.

Comfort, L.K. and Kapucu, N. (2006) 'Inter-Organizational Coordination in Extreme Events : The World Trade Center Attacks, September 11, 2001'. Natural Hazards, (39), pp. 
309-327. DOI: 10.1007/s11069-006-0030-x.

Creswell, J. (2014) Research Design: Qualitative, Quantitative \& Mixed Methods Approaches. 4th Edition. Thousand Oaks, CA: Sage.

Dahlberg, R. (2017) 'Who Is in the Center? A Case Study of a Social Network in an Emergency Management Organization'. International Journal of Emergency Services, 6(1), pp. 52-66. DOI: 10.1108/IJES-07-2016-0013.

Deffenbacher, K. et al. (2004) 'A Meta-Analytic Review of the Effects of High Stress on Eyewitness Memory.' Law and Human Behavior, 28(6), pp. 687-706. DOI: 10.1007/s10979-004-0565-x.

Denzin, N.K. (1978) The Research Act. 2nd Edition. New York: McGraw-Hill DOI: 10.4324/9781315134543.

Denzin, N.K. (2012) 'Triangulation 2.0'. Journal of Mixed Methods Research, 6(2011), pp. 80-88. DOI: 10.1177/1558689812437186.

Dorasamy, M. et al. (2008) 'Knowledge Management for Disaster Response : A Proposed Framework'. In Hashim, N.L. et al. (eds.) In Proceedings of Knowledge Management International Conference 2008 (KMICE). Langkawi, Malaysia: Universiti Utara Malaysia, pp. 257-263.

Dubois, A. and Gibbert, M. (2010) 'From Complexity to Transparency: Managing the Interplay between Theory, Method and Empirical Phenomena in IMM Case Studies'. Industrial Marketing Management, 39(1), pp. 129-136. DOI:

10.1016/j.indmarman.2009.08.003.

Dunn, J.C., Lewandowsky, S. and Kirsner, K. (2002) 'Dynamics of Communication in Emergency Management'. Applied Cognitive Psychology, 16(6), pp. 719-737. DOI: 10.1002/acp.846.

Edzen, S. and Sein, M. (2016) 'Designing Theme-Based Tabletop Exercise for 
Identifying and Dealing with Coordination Problems in Emergencies'. International Journal Of Emergency Management, 12(1), pp. 22-40. DOI: 10.1504/IJEM.2016.074883.

Eide, A.W. et al. (2012) 'Key Challenges in Multi-Agency Collaboration during LargeScale Emergency Management'. In Proceedings of the International Joint Conference on Ambient Intelligence. Pisa, Italy.

Fetters, M.D., Curry, L.A. and Creswell, J.W. (2013) 'Achieving Integration in Mixed Methods Designs - Principles and Practices'. Health Services Research, 48(6 PART2), pp. 2134-2156. DOI: 10.1111/1475-6773.12117.

Franco, Z.E. et al. (2009) 'Evaluating the Impact of Improvisation on the Incident Command System : A Modified Single Case Study Using the DDD Simulator'. In Landgren, J. and Jul, S. (eds.) Proceedings of the 6th International ISCRAM Conference. Gothenburg, Sweden.

Gibbert, M. and Ruigrok, W. (2010) 'The "What" and "How" of Case Study Rigor: Three Strategies Based on Published Work'. Organizational Research Methods, 13(4), pp. 710-737. DOI: 10.1177/1094428109351319.

Glasgow, S.M. et al. (2018) 'Development of a Discrete Event Simulation Model for Evaluating Strategies of Red Blood Cell Provision Following Mass Casualty Events'. European Journal of Operational Research, 270(1), pp. 362-374. DOI: 10.1016/j.ejor.2018.03.008.

Groenendaal, J. and Helsloot, I. (2018) 'A Closer Examination of Command and Control Practices by Incident Commanders during Realistic Operational Exercises in the Netherlands'. International Journal of Emergency Management, 14(1), pp. 51-71. DOI: 10.1504/IJEM.2018.089159.

Groenendaal, J. and Helsloot, I. (2016) 'A Preliminary Examination of Command and Control by Incident Commanders of Dutch Fire Services during Real Incidents'. Journal of Contingencies and Crisis Management, 24(1). DOI: 10.1111/1468-5973.12096. 
Groenendaal, J., Helsloot, I. and Scholtens, A. (2013) 'A Critical Examination of the Assumptions Regarding Centralized Coordination in Large-Scale Emergency Situations'. Journal of Homeland Security and Emergency Management, 10(1), pp. 113-135. DOI: 10.1515/jhsem-2012-0053.

Grunwald, J.A. and Bearman, C. (2017) 'Identifying and Resolving Coordinated Decision Making Breakdowns in Emergency Management'. International Journal of Emergency Management, 13(1), pp. 68-89. DOI: 10.1504/ijem.2017.081198.

Guetterman, T.C., Fetters, M.D. and Creswell, J.W. (2015) 'Integrating Quantitative and Qualitative Results in Health Science Mixed Methods Research Through Joint Displays'. Annals of Family Medicine, 13(6), pp. 554-561. DOI: 10.1370/afm.1865.

Haar, S. Van Der., Segers, M. and Jehn, K.A. (2013) 'Measuring the Effectiveness of Emergency Management Teams: Scale Development and Validation'. International Journal of Emergency Management, 9(3), p. 258. DOI: 10.1504/IJEM.2013.058547.

Hancox, G. et al. (2018) 'Systems Mapping for Technology Development in CBRN Response'. International Journal of Emergency Services, 7(2), pp. 111-119. DOI: 10.1108/IJES-08-2017-0044.

Harrald, J.R. (2006) 'Agility and Discipline: Critical Success Factors for Disaster Response'. The Annals of the American Academy of Political and Social Science, 604(1), pp. 256-272. DOI: 10.1177/0002716205285404.

Hawe, G.I. et al. (2012) 'Agent-Based Simulation for Large-Scale Emergency Response'. ACM Computing Surveys, 45(1), pp. 1-51. DOI: 10.1145/2379776.2379784.

Heckathorn, D.D. (1997) 'Respondent-Driven Sampling: A New Approach to the Study of Hidden Populations'. Social Problems, 44(2), pp. 174-199. DOI: 10.1525/sp.1997.44.2.03×0221m.

Hope, L. et al. (2016) 'Memory and the Operational Witness : Police Officer Recall of Firearms Encounters as a Function of Active Response Role'. Law and Human Behavior, 
40(1), pp. 23-35. DOI: 10.1037//hb0000159.

Hope, L. et al. (2012) 'Witnesses in Action: The Effect of Physical Exertion on Recall and Recognition.' Psychological Science, 23(4), pp. 386-90. DOI:

10.1177/0956797611431463.

Houghton, R.J. et al. (2006) 'Command and Control in Emergency Services Operations: A Social Network Analysis.' Ergonomics, 49(12-13), pp. 1204-25. DOI: 10.1080/00140130600619528.

Hsiieh, H.-F. and Shannon, S.E. (2005) 'Three Approaches to Qualitative Content Analysis'. Qualitative Health Research, 15(9), pp. 1277-1288. DOI: $10.1177 / 1049732305276687$.

Janssen, M. et al. (2009) 'Advances in Multi-Agency Disaster Management: Key Elements in Disaster Research'. Information Systems Frontiers, 12(1), pp. 1-7. DOI: 10.1007/s10796-009-9176-x.

Jensen, J. and Thompson, S. (2016) 'The Incident Command System: A Literature Review'. Disasters, 40(1), pp. 158-182. DOI: 10.1111/disa.12135.

Kapucu, N. (2005) 'Interorganizational Coordination in Dynamic Context : Networks in Emergency Response'. Connections, 26(2), pp. 33-48. DOI: 10.1.1.126.5923.

Kristiansen, E. et al. (2017) 'Time to Rethink Norwegian Maritime Collaboration Exercises'. International Journal of Emergency Services, 6(1), pp. 14-28. DOI: 10.1108/IJES-07-2016-0014.

Krohwinkel, A. (2015) 'A Configurational Approach to Project Delays: Evidence From a Sequential Mixed Methods Study'. Journal of Mixed Methods Research, 9(4), pp. 335-361. DOI: $10.1177 / 1558689814522709$.

Lindell, M.K., Perry, R.W. and Prater, C.S. (2005) 'Organizing Response to Disasters with the Incident Command System / Incident Management System ( ICS / IMS )'. In 
International Workshop on Emergency Response and Rescue.

Luyt, R. (2012) 'A Framework for Mixing Methods in Quantitative Measurement Development, Validation, and Revision: A Case Study'. Journal of Mixed Methods Research, 6(4), pp. 294-316. DOI: 10.1177/1558689811427912.

Malone, W. (1993) ‘Research Definition and Location of Research: A User’s View’. International Journal of Mass Emergencies and Disasters, 11(1), pp. 63-74.

Maxwell, J.A. (1992) ‘Understanding and Validity in Qualitative Research'. Harvard Educational Review, 62(3), pp. 279-300.

McEntire, D.A. and Marshall, M. (2003) 'Epistemological Problems in EM'. American Society of Professional Emergency Planners, 10, pp. 119-129.

Mertens, D.M. (2015) 'Mixed Methods and Wicked Problems'. Journal of Mixed Methods Research, 9(1), pp. 1-4. DOI: 10.1177/1558689814562944.

Mishra, J.L., Allen, D.K. and Pearman, A.D. (2015) 'Understanding Decision Making during Emergencies : A Key Contributor to Resilience'. EURO Journal on Decision Processes, 3(3), pp. 397-424. DOI: 10.1007/s40070-015-0039-z.

Molina-Azorín, J.F. and Cameron, R. (2010) 'The Application of Mixed Methods in Organisational Research: A Literature Review'. Electronic Journal of Business Research Methods, 8(2), pp. 95-105. Available at: MM; Organisational; UnRead; MMA.

Morgan, C.A. and Southwick, S. (2014) 'Perspective: I Believe What I Remember, but It May Not Be True'. Neurobiology of Learning and Memory, 112, pp. 101-103. DOI: 10.1016/j.nlm.2013.12.011.

Moynihan, D.P. (2009) 'From Intercrisis To Intracrisis Learning'. Journal of Contingencies and Crisis Management, 17(3), pp. 189-198.

Najmaei, A. (2016) 'Using Mixed-Methods Designs to Capture the Essence of Complexity in the Entrepreneurship Research: An Introductory Essay and a Research 
Agenda'. In Berger, E.S.C. and Kuckertz, A. (eds.) Complexity in Entrepreneurship, Innovation and Technology Research. Switzerland: Springer International Publishing, pp. 63-92. DOI: 10.1007/978-3-319-27108-8.

Neal, D.M. (1993) 'Intgrating Disaster Research and Practice: An Overview of Issues'. International Journal of Mass Emergencies and Disasters, 11(1), pp. 5-13.

Newman, M.E.J. (2010) Networks an Introduction. Oxford, UK.: Oxford University press.

Perry, R.W. and Quarantelli, E.L. (2007) What Is a Disaster? New Answers to Old Questions. Available at: http://link.springer.com/chapter/10.1007/978-0-387-32353-4_1.

Pollock, K. (2013).

Quarantelli, E.L. (1993) ‘Converting Disaster Scholarship into Effective Disaster Planning and Managing Possibilities and Limitations'. International Journal of Mass Emergencies and Disasters, 11(1), pp. 15-39.

Quarantelli, E.L. (1997) 'Field Studies of Organized Behavior in the Crisis Time Period of Disasters'. 15(1), pp. 1-22.

Rimstad, R. et al. (2014) 'Incident Command and Information Flows in a Large-Scale Emergency Operation'. Journal of Contingencies and Crisis Management, 22(1), pp. 29-38.

Ryan, B. (2017) 'The Significance of Communication in Emergency Management: What's Changed since 2010?' Australian Journal of Emergency Management, 32(1), pp. 2431.

Skertich, R. (2008) Action and Information Networks in Disaster Management. University of Pittsburgh 2008.

Skryabina, E.A. et al. (2020) 'The Role of Emergency Preparedness Exercises in the Response to a Mass Casualty Terrorist Incident: A Mixed Methods Study'. International Journal of Disaster Risk Reduction, 46(January). DOI: 10.1016/j.ijdrr.2020.101503. 
Strandh, V. (2015) 'Preparing and Responding to Mass-Casualty Terrorist Attacks: A Comparative Analysis of Four Terrorist Attacks Targeting Rail Bound Traffic'. International Journal of Emergency Management, 11(3), p. 262. DOI: 10.1504/IJEM.2015.071709.

Strom, K.J. and Eyerman, J. (2008) 'Interagency Coordination: A Case Study of the 2005 London Train Bombings'. National Institute of Justice, (260), pp. 8-11.

Tierney, K. (2009) Disaster Response: Research Findings and Their Implications for Resilience Measures. Boulder, Colorado.

Trainor, Joseph E., Stern, E.K. and Subbio, T. (2018) ‘On Bridging Research and Practice in Disaster Science and Management: Unified System or Impossible Mission?' In Rodrıguez, H.Donner, W.and Trainor, J.E. (eds.) Handbook of Disaster Research. Berlin: Springer, pp. 161-178. DOI: 10.1007/978-3-319-63254-4.

Uhr, C. (2009) Multi-Organizational Emergency Response Management - A Framework for Further Development for Further Development. Lund University.

Uhr, C. and Johansson, H. (2007) 'Mapping an Emergency Management Network'. International Journal of Emergency Management, 4(1), pp. 104-118. DOI: 10.1504/IJEM.2007.012392.

Wankhade, P. and Murphy, P. (2012) 'Bridging the Theory and Practice Gap in Emergency Services Research: A Case for a New Journal'. International Journal of Emergency Services, 1(1), pp. 4-9. DOI: 10.1108/20470891211239281.

Witt, E. and Lill, I. (2018) 'Methodologies of Contemporary Disaster Resilience Research'. Procedia Engineering, 212, pp. 970-977. DOI: 10.1016/j.proeng.2018.01.125.

Wolbers, J. and Boersma, K. (2013) 'The Common Operational Picture as Collective Sensemaking'. Journal of Contingencies \& Crisis Management, 21(4), pp. 186-199.

Wybo, J.L. (2008) 'The Role of Simulation Exercises in the Assessment of Robustness and Resilience of Private Or'. In Pasman, H.J. and Kirillov, I.A. (eds.) Resilience 
of Cities to Terrorist and Other Threats: Learning from 9/11 and Further Research Issues. Dordrecht: Springer, pp. 491-507. DOI: 10.1007/978-1-4020-8489-8.

Yin, R.K. (2014) Case Study Research: Design and Methods. 5th Edition. SAGE DOI: 10.1097/00005053-199102000-00025.

Zhang, Y. and Wildemuth, B.M. (2009) 'Qualitative Analysis of Content'. In Wildemuth, B. (ed.) Applications of Social Research Methods to Questions in Information and Library Science. Westport, CT: Libraries Unlimited, pp. 308-319. DOI: 10.1002/hbm.20661.

Zhou, Q., Huang, W. and Zhang, Y. (2011) 'Identifying Critical Success Factors in Emergency Management Using a Fuzzy DEMATEL Method'. Safety Science, 49(2), pp. 243-252. DOI: 10.1016/j.ssci.2010.08.005. 


\section{Appendix}

Appendix A - Summary of Coroner's Inquest Evidence Document Types Providing Source Data.

\begin{tabular}{|c|c|c|c|c|}
\hline Category & Type & Source & Description & Data Type \\
\hline \multirow[t]{2}{*}{$\begin{array}{l}\text { Primary } \\
\text { Evidence } \\
\text { (generated } \\
\text { during } \\
\text { response) }\end{array}$} & Command Logs & Organizational & $\begin{array}{l}\text { Recorded by responders as part of the } \\
\text { Command and Control function. Capturing } \\
\text { activities undertaken, communication, and the } \\
\text { timing of key events. Presented as either } \\
\text { handwritten or electronic logs. }\end{array}$ & $\begin{array}{l}\text { QUAN } \\
\text { Objective quantitative data recording } \\
\text { key events (decisions, communication, } \\
\text { task outcomes), personnel undertaking } \\
\text { key command roles. } \\
\text { Qual } \\
\text { Some observations and task } \\
\text { descriptions recorded when provided } \\
\text { as situation update messages }\end{array}$ \\
\hline & $\begin{array}{l}\text { Control } \\
\text { Records }\end{array}$ & Organizational & $\begin{array}{l}\text { Electronic records maintained by organizational } \\
\text { control rooms to support response coordination. } \\
\text { Typically capture resource mobilisation and } \\
\text { location, requests for information or further } \\
\text { resources, and brief situation updates. }\end{array}$ & $\begin{array}{l}\text { QUAN } \\
\text { Time stamped reports of vehicle and } \\
\text { personnel location, communication, } \\
\text { key events and personnel command } \\
\text { roles. } \\
\text { Qual } \\
\text { Some observations and task } \\
\text { descriptions recorded when provided } \\
\text { as situation update messages }\end{array}$ \\
\hline
\end{tabular}




\begin{tabular}{|c|c|c|c|c|}
\hline & $\begin{array}{l}\text { Message } \\
\text { Transcripts }\end{array}$ & Organizational & $\begin{array}{l}\text { Transcribed from audio recordings of } \\
\text { conversations, predominantly involving Control } \\
\text { room personnel. }\end{array}$ & $\begin{array}{l}\text { QUAL } \\
\text { Descriptions of key events and tasks } \\
\text { Quan } \\
\text { Timing of communication }\end{array}$ \\
\hline & $\begin{array}{c}\text { Personal } \\
\text { Decision \& } \\
\text { Incident Logs }\end{array}$ & Individual & $\begin{array}{l}\text { Contemporaneous notes in blank and structured } \\
\text { pro-forma notebooks recorded by specific } \\
\text { personnel (usually senior managers) capturing } \\
\text { records of conversations, actions, tasks, } \\
\text { locations, etc. }\end{array}$ & $\begin{array}{l}\text { QUAL } \\
\text { Summary of content of communication } \\
\text { and description of tasks and decisions. } \\
\text { Quan } \\
\text { Timing of key events and } \\
\text { communication. }\end{array}$ \\
\hline \multirow[t]{2}{*}{$\begin{array}{l}\text { Secondary } \\
\text { (generated } \\
\text { after } \\
\text { response) }\end{array}$} & $\begin{array}{l}\text { Individual } \\
\text { Debrief } \\
\text { Records }\end{array}$ & Individual & $\begin{array}{l}\text { Completed by emergency responders following } \\
\text { incident. Representing a type of questionnaire } \\
\text { capturing personal details, command roles } \\
\text { undertaken, and free text explanations under } \\
\text { open subject headings. }\end{array}$ & $\begin{array}{l}\text { QUAL } \\
\text { Structured, qualitative description of } \\
\text { objective ERM network attributes } \\
\text { (communication, task, etc) and } \\
\text { subjective observations and } \\
\text { comments. } \\
\text { Quan } \\
\text { Timing of locations attended and order } \\
\text { of events }\end{array}$ \\
\hline & $\begin{array}{l}\text { Organizational } \\
\text { Debrief } \\
\text { Records }\end{array}$ & Organizational & $\begin{array}{l}\text { Reports collated either at meetings (representing } \\
\text { a type of focus group) or gathered by other } \\
\text { means including email. Recorded as bespoke } \\
\text { reports structured around key issues, on } \\
\text { standardized forms, or as records of email } \\
\text { conversations. }\end{array}$ & $\begin{array}{l}\text { QUAL } \\
\text { Subjective comment relating to key } \\
\text { events and causal factors of incident } \\
\text { and aspects of response structure } \\
\text { Quan }\end{array}$ \\
\hline
\end{tabular}




\begin{tabular}{|c|l|l|l|l|}
\hline & & & & $\begin{array}{l}\text { Confirmation of order of events and } \\
\text { tasks. }\end{array}$ \\
\cline { 2 - 5 } & $\begin{array}{c}\text { Witness } \\
\text { Statements }\end{array}$ & Individual & $\begin{array}{l}\text { Provided by responders to support investigation, } \\
\text { constituted unstructured free text explanations of } \\
\text { what occurred, what the individual did and what } \\
\text { they saw. }\end{array}$ & $\begin{array}{l}\text { QUAL } \\
\text { Unstructured, qualitative descriptions } \\
\text { of objective ERM network attributes } \\
\text { (communication, task, etc), subjective } \\
\text { observations and comments } \\
\text { Quan } \\
\text { Reported locations and communication }\end{array}$ \\
$\begin{array}{c}\text { Hearing } \\
\text { (transcription } \\
\text { of Coroner's } \\
\begin{array}{c}\text { Inquest } \\
\text { Hearing) }\end{array}\end{array}$ & $\begin{array}{c}\text { Witness } \\
\text { Testimony }\end{array}$ & Individual & $\begin{array}{l}\text { Transcribed testimony of responders during } \\
\text { Hearing. Consisting of directed questioning } \\
\text { (under oath by solicitors) to confirm details } \\
\text { gathered previously, eliciting subjective } \\
\text { observations and clarify greater detail }\end{array}$ & $\begin{array}{l}\text { QUAL } \\
\text { Provided responders Observations } \\
\text { and subjective Comments relating to } \\
\text { ERM system. } \\
\text { Quan }\end{array}$ \\
\end{tabular}




\section{Appendix B - ERM Task-Data Framework}

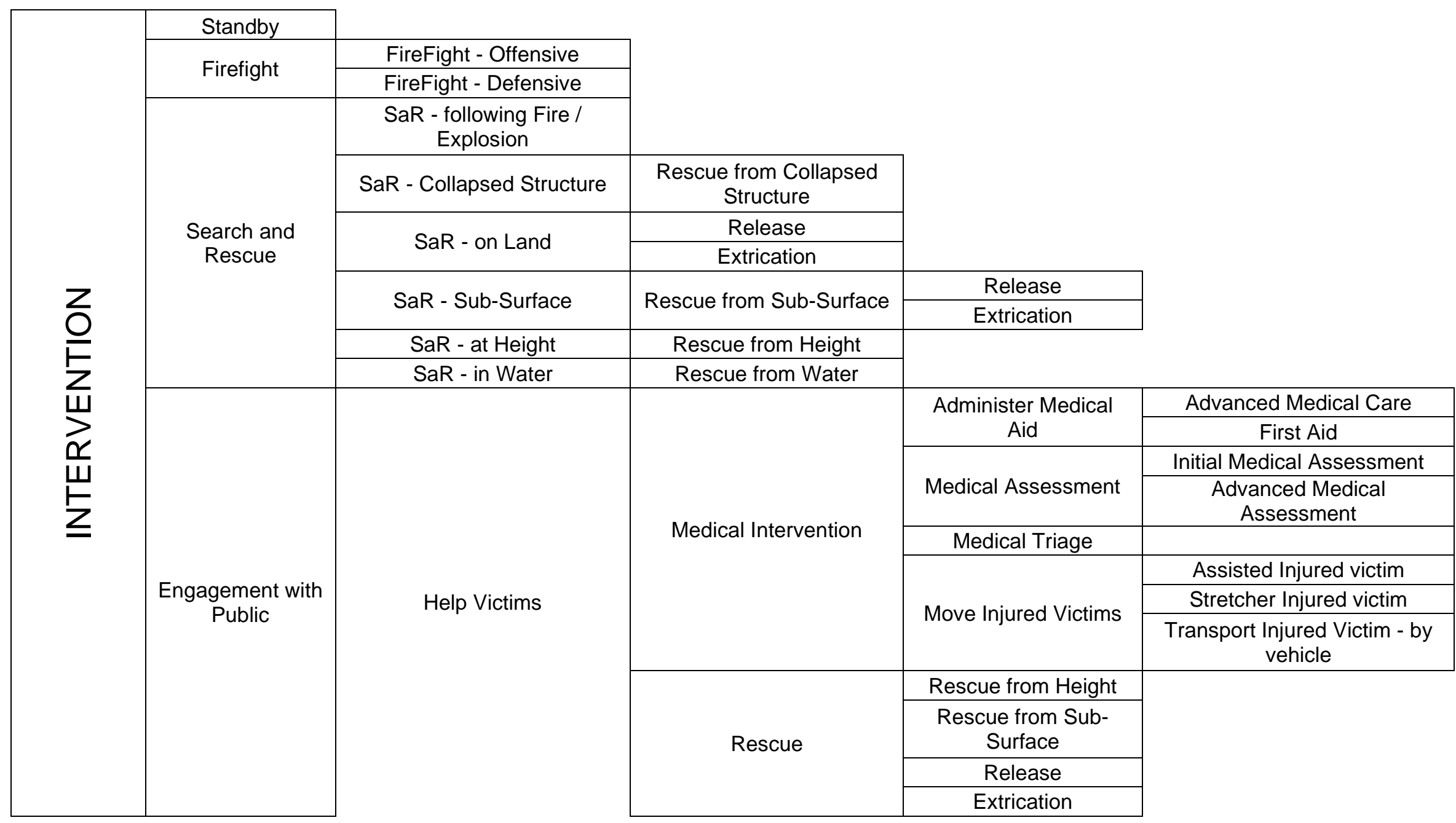




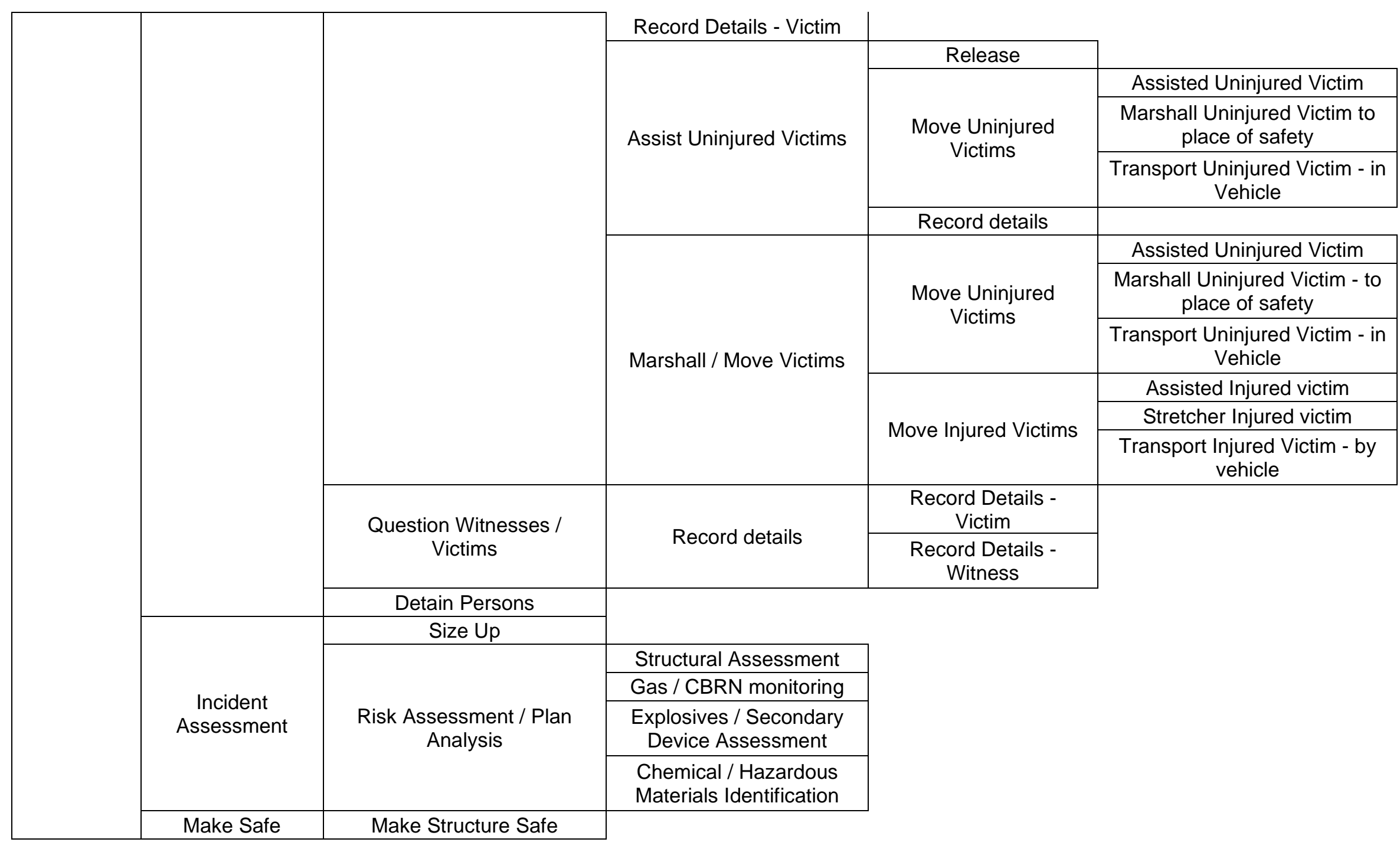




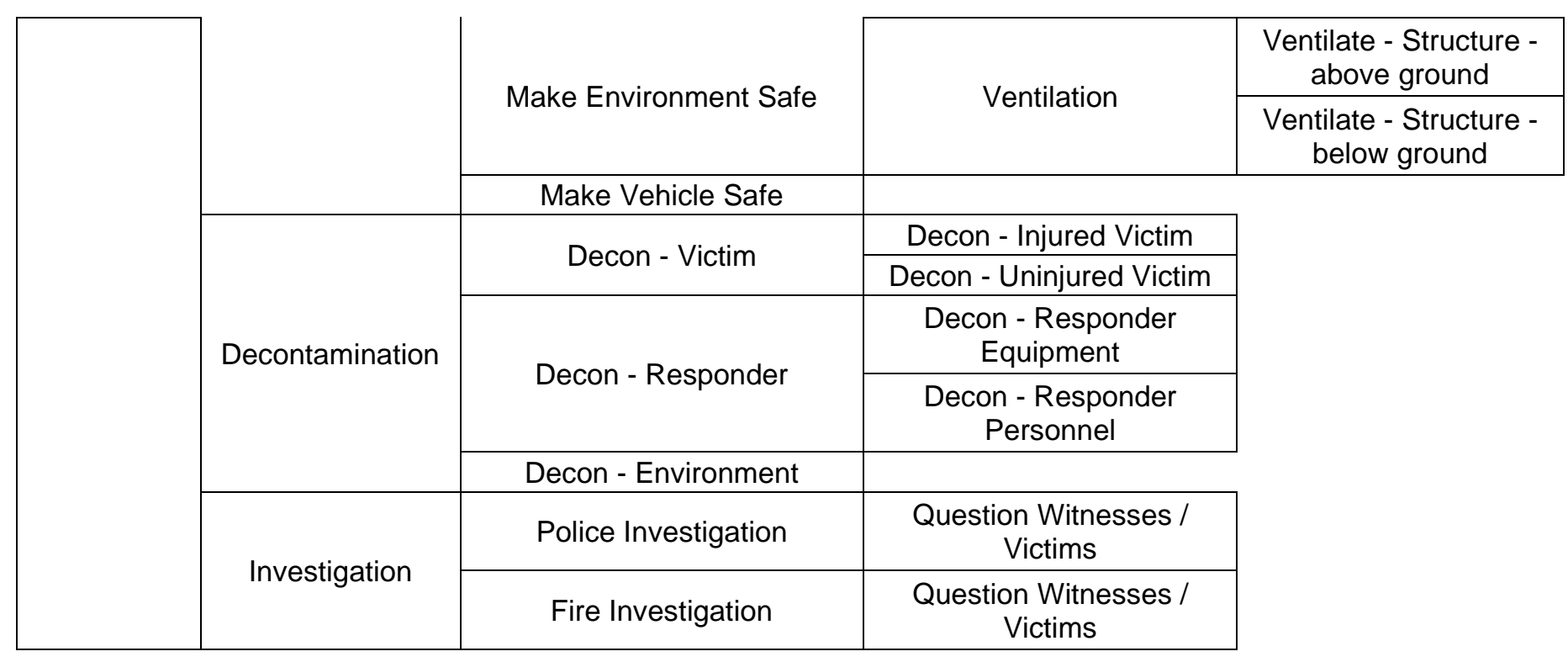




\begin{tabular}{|c|c|c|c|}
\hline \multirow{16}{*}{ 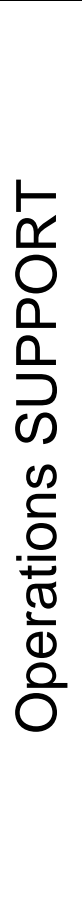 } & $\begin{array}{c}\text { Standby } \\
\text { Make Ready } \\
\text { Resources }\end{array}$ & & \\
\hline & \multirow{4}{*}{$\begin{array}{l}\text { Response } \\
\text { Transport }\end{array}$} & Transport Personnel & \\
\hline & & \multirow{2}{*}{ Transport Equipment } & Transport Equipment - by Person \\
\hline & & & Transport Equipment - by Vehicle \\
\hline & & Escort Vehicles & \\
\hline & \multirow{5}{*}{$\begin{array}{l}\text { Scene Safety / } \\
\text { Control }\end{array}$} & \multirow{3}{*}{ Cordon Control } & Control - Inner Cordon \\
\hline & & & Control - Outer Cordon \\
\hline & & & Cordon Gateway Management \\
\hline & & Road Closure & \\
\hline & & Safety Monitoring & \\
\hline & \multirow{3}{*}{$\begin{array}{c}\text { Resource } \\
\text { Control }\end{array}$} & \multirow{2}{*}{ Marshall Resources (make ready) } & Marshall - Vehicle / Equipment \\
\hline & & & Marshall - Personnel \\
\hline & & Deploy Resources & \\
\hline & \multirow{3}{*}{$\begin{array}{l}\text { Gather Tactical } \\
\text { Incident } \\
\text { Information }\end{array}$} & From On-Site Person & \\
\hline & & Size Up & \\
\hline & & Gather OWN Site / Incident Specific Info & \\
\hline
\end{tabular}




\begin{tabular}{|c|c|c|c|}
\hline \multirow{11}{*}{ 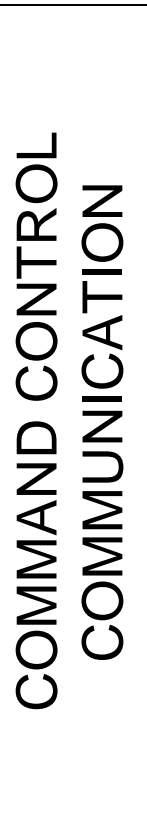 } & \multirow{9}{*}{ Communication } & Comms - Runner & \\
\hline & & \multirow{2}{*}{ Comms - External } & Communicate - to Public \\
\hline & & & Communicate - to Media \\
\hline & & \multirow{4}{*}{ Comms - Internal } & Communicate - Plan Brief \\
\hline & & & Communicate - Situational Update \\
\hline & & & Communicate - Request Resources \\
\hline & & & Handover Command \\
\hline & & \multirow[b]{2}{*}{ Comms - Inter-Agency } & Comms - Inform Other Agency \\
\hline & & & $\begin{array}{c}\text { Comms - Liaise / Coordinate with } \\
\text { Other Agency }\end{array}$ \\
\hline & \multirow{2}{*}{ Recording } & Logging Incident Information & \\
\hline & & Gathering / Confirming Incident Information & \\
\hline
\end{tabular}

